Supplement of The Cryosphere, 15, 17-30, 2021 https://doi.org/10.5194/tc-15-17-2021-supplement (C) Author(s) 2021. This work is distributed under the Creative Commons Attribution 4.0 License.

(c) (i)

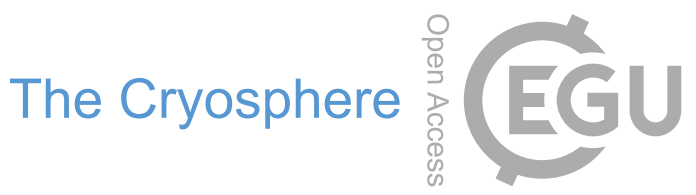

Supplement of

\title{
Subglacial carbonate deposits as a potential proxy for a glacier's former presence
}

Matej Lipar et al.

Correspondence to: Matej Lipar (matej.lipar@zrc-sazu.si)

The copyright of individual parts of the supplement might differ from the CC BY 4.0 License. 
Supplementary Figure S1: Photographic material of the retreating Triglav Glacier (@ ZRC SAZU Anton Melik Geographical Institute archive).
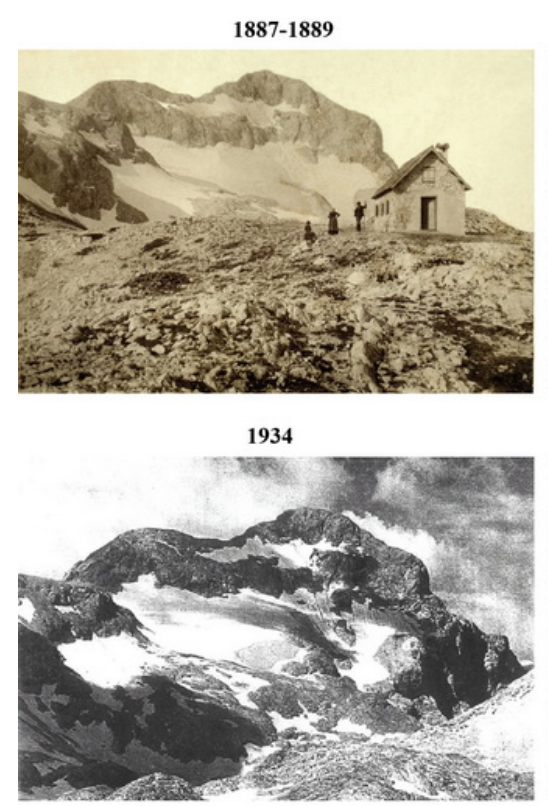

1959

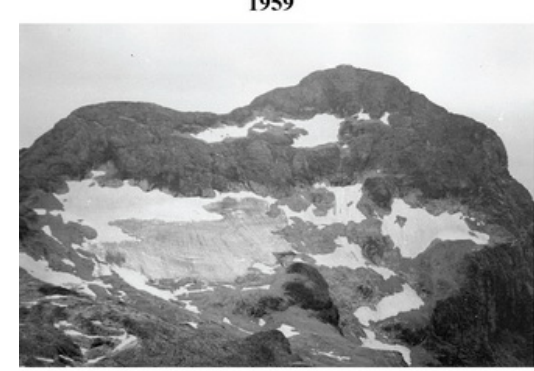

1990

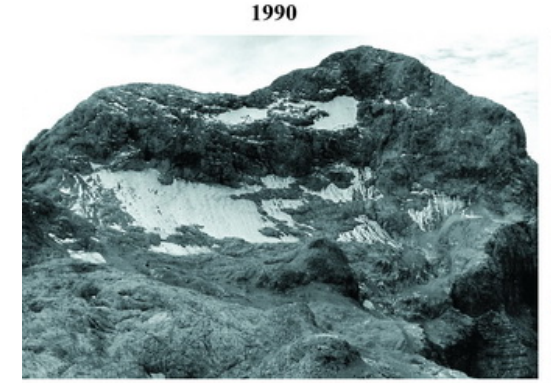

2005

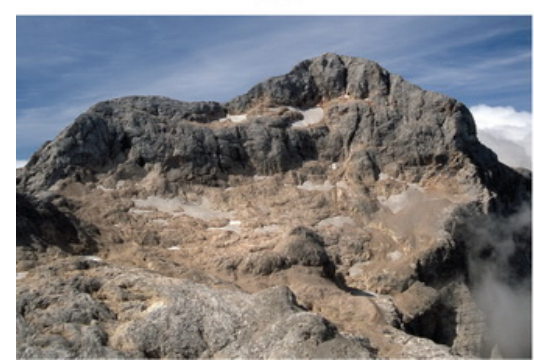

1897

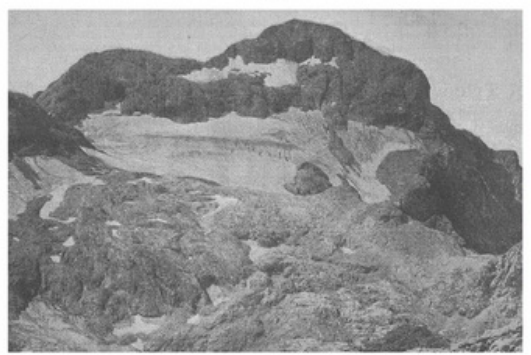

1946

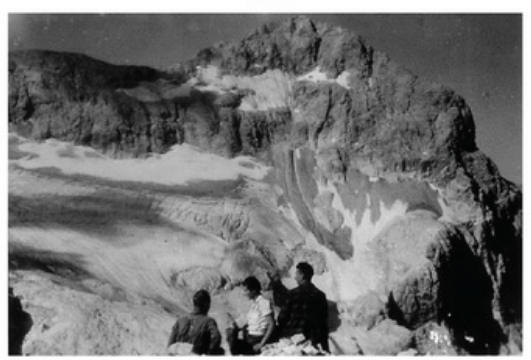

1975

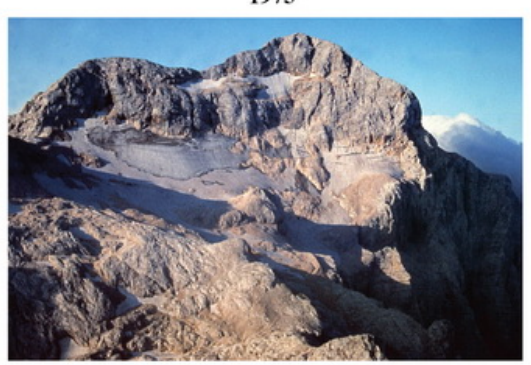

1995

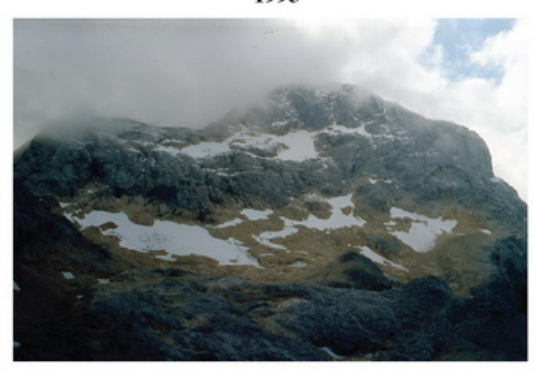

2011

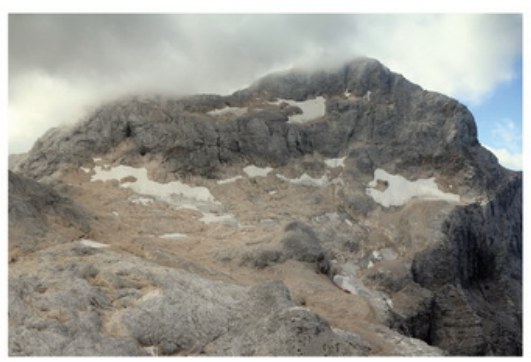

1932

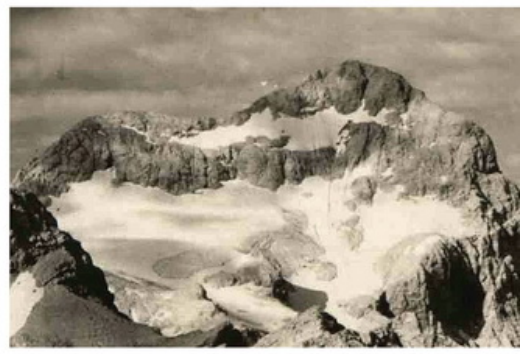

1954

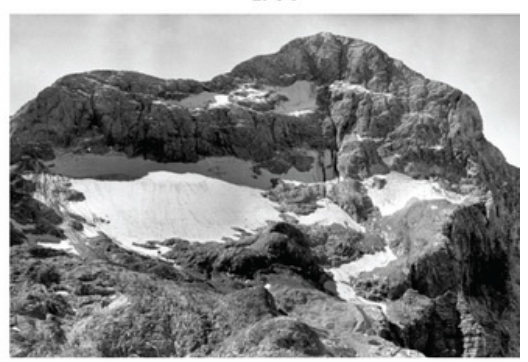

1987

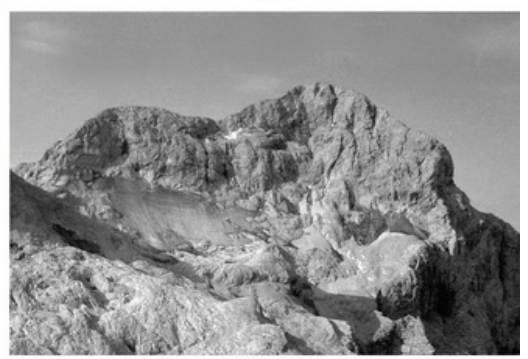

1999

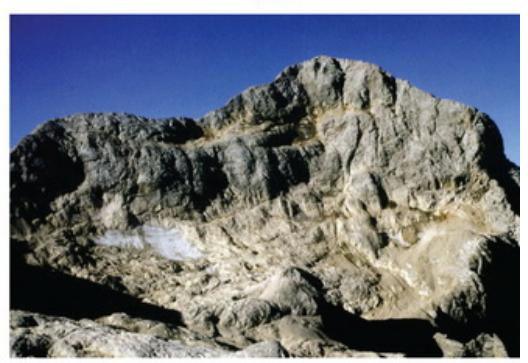

2017

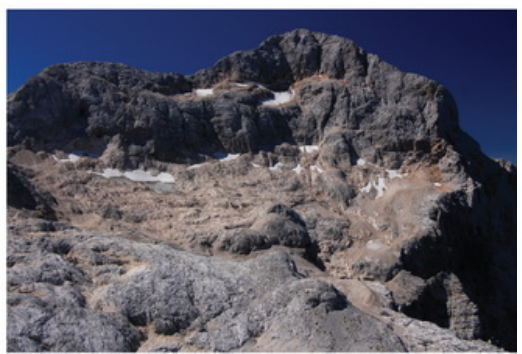


Supplementary Figure S2: Locality aerial map of the Triglav Glacier, the sampling sites discussed in the text, and general geomorphology.

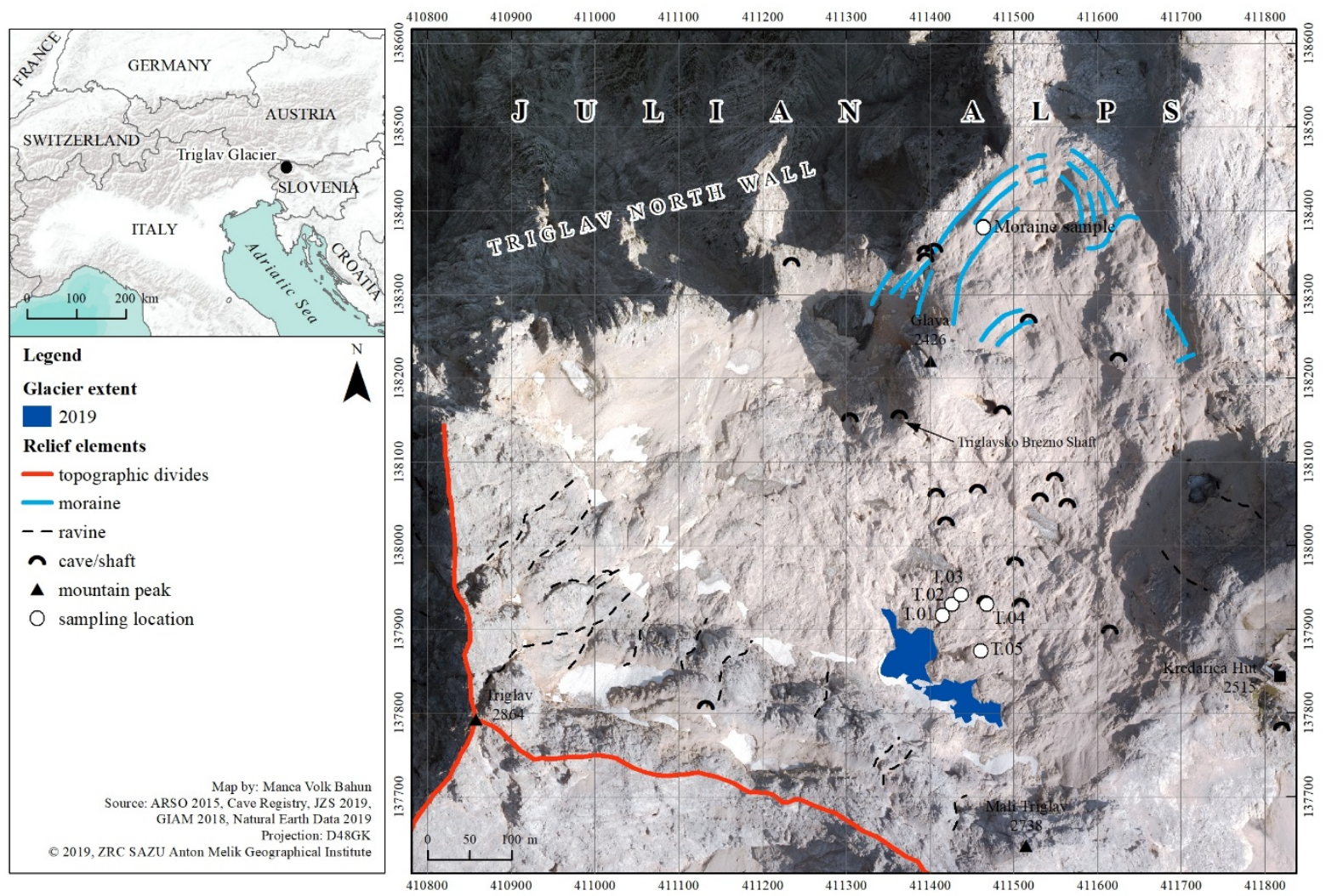

Supplementary Figure S3: Average ablation season temperature (May - October) on meteorological station Kredarica (Fig. 1) between 1955 and 2018. Data source: Slovenian Environment Agency.

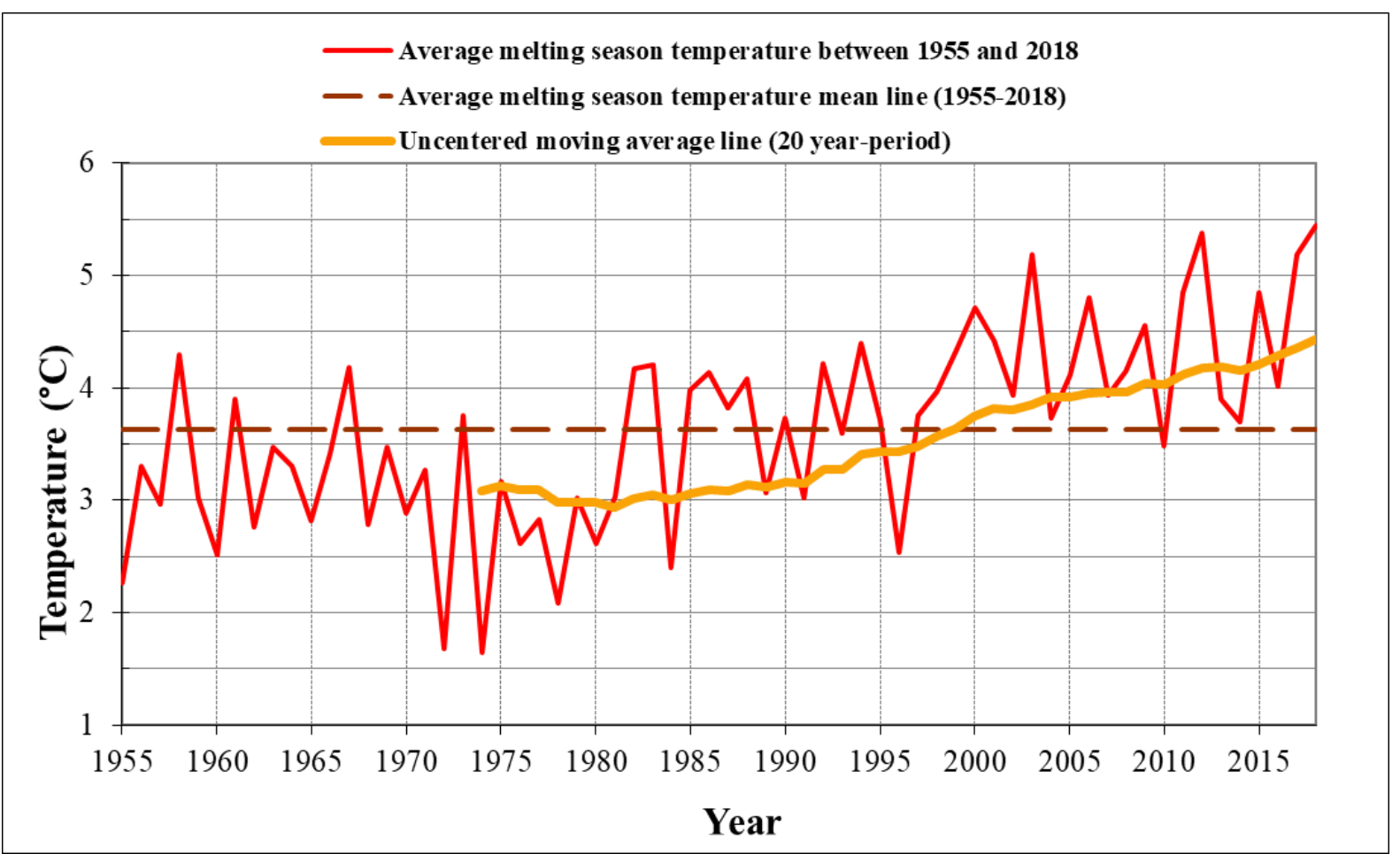


Supplementary Figure S4: Reconstruction of the highest seasonal snow height on the edge of the Triglav Glacier between 1852 and 2018 updated from Gabrovec et al. (2014) (source: Slovenian Environment Agency (from 1955 on), reconstruction/reanalysis before 1955 done by Jaka Ortar).

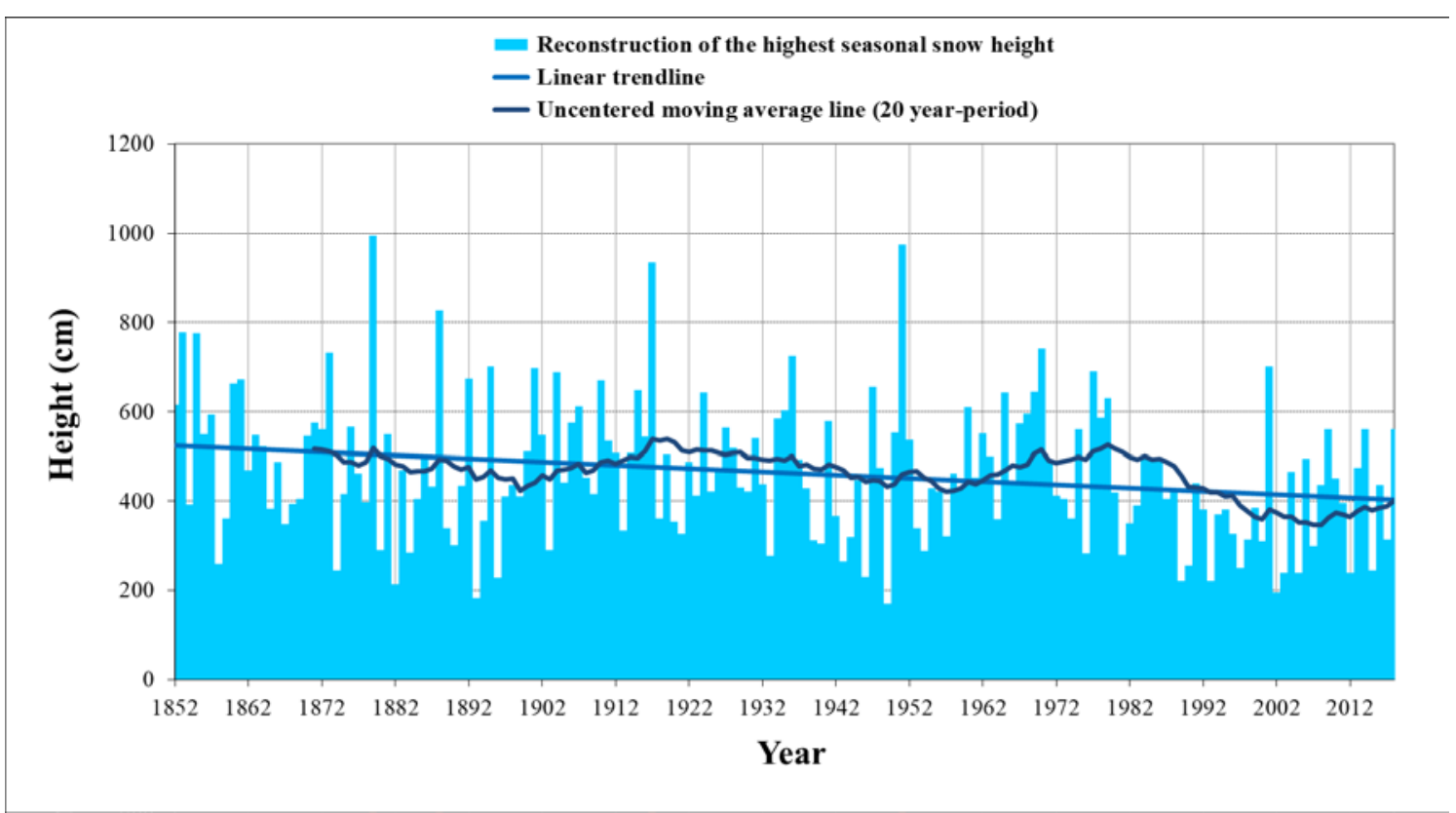


Supplementary Figure S5: XRD diagrams of all the studied samples (for precise location, see Figure 3 in the main manuscript). Samples TRG-01 C and TRG-03 D correspond to the bed rock. Green lines mark the reflections corresponding to calcite, and red lines mark the reflections of those corresponding to aragonite.

\section{TRG-01 A}

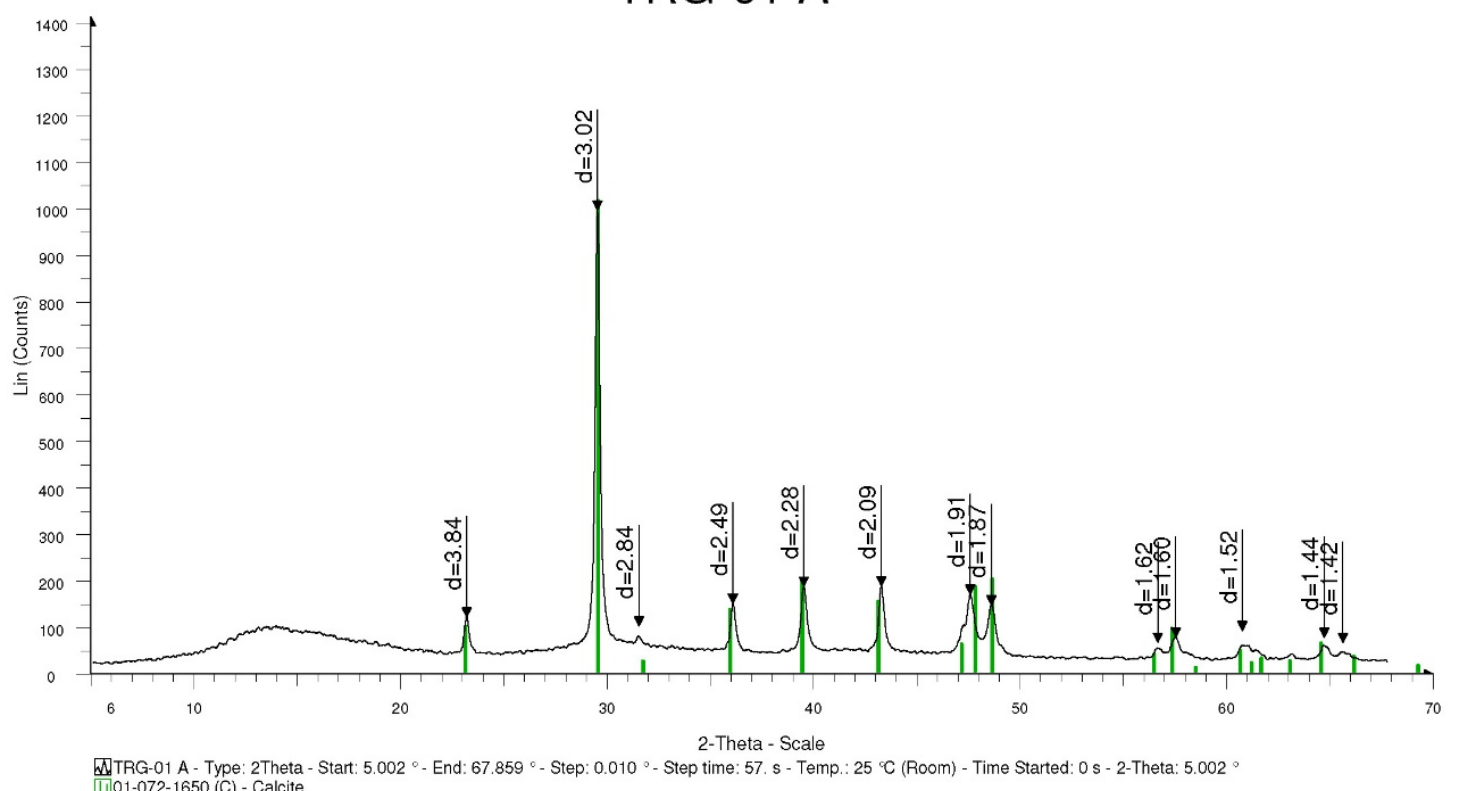

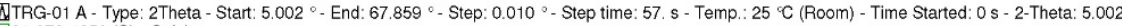

\section{TRG-01 B}

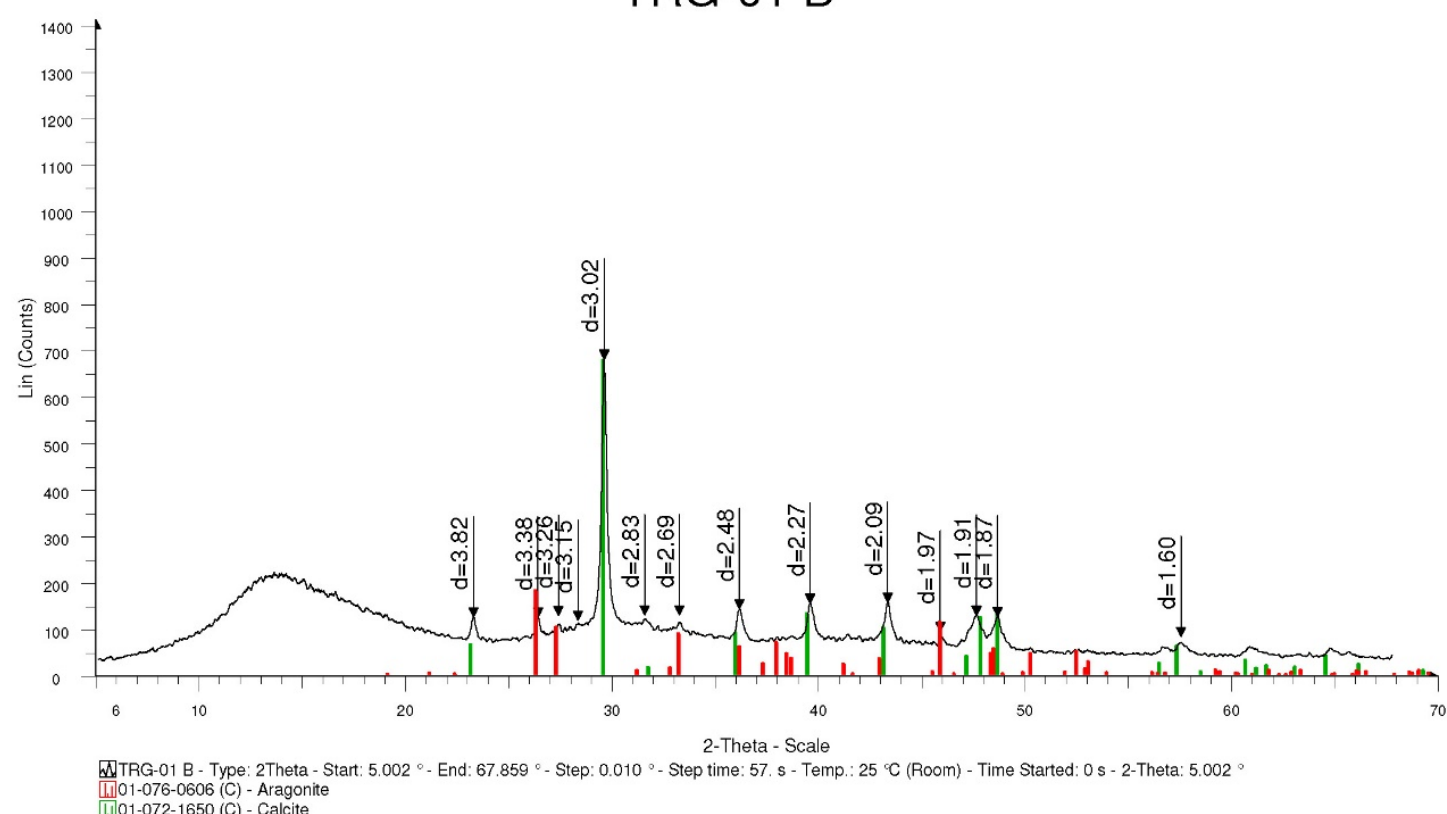




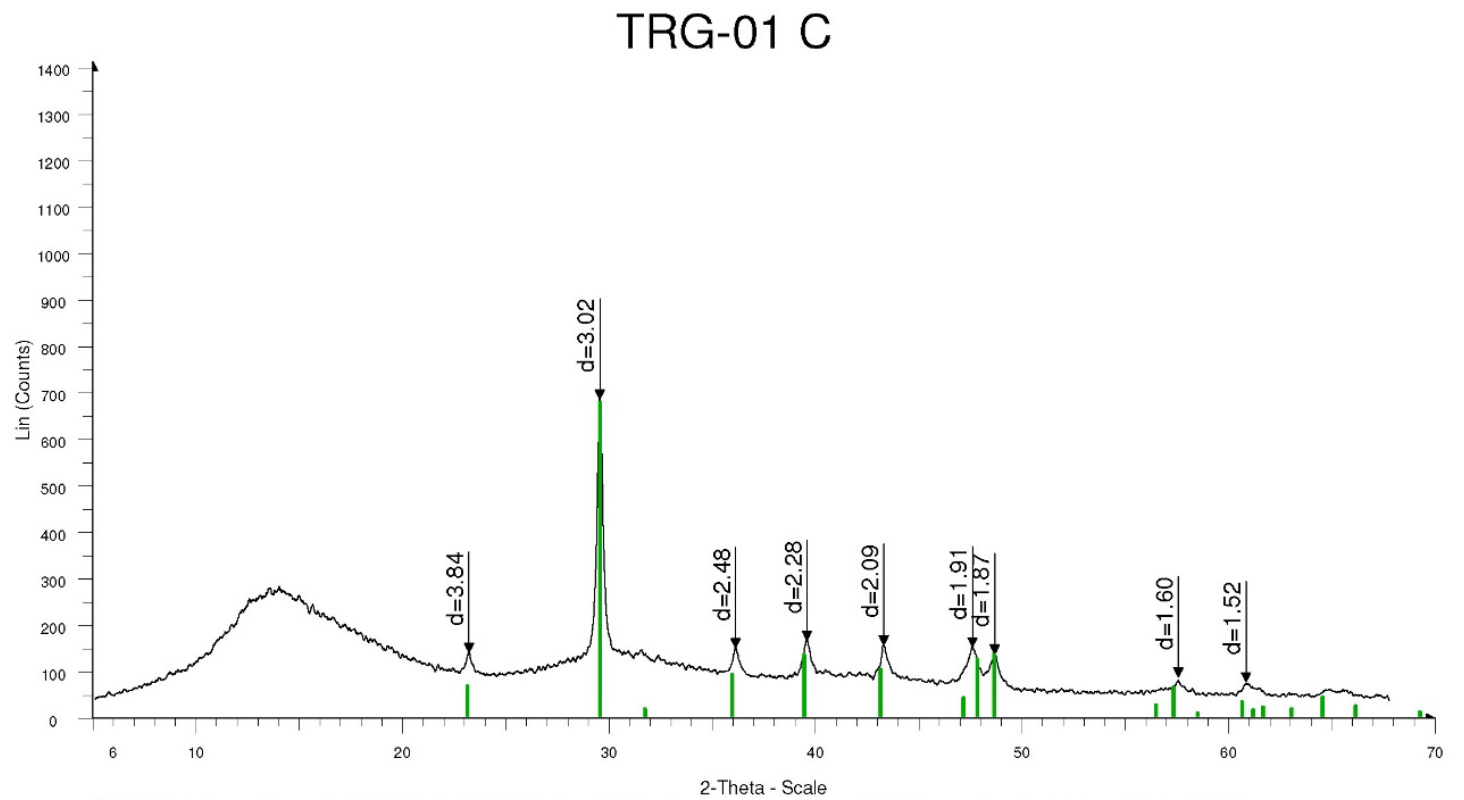

WTRG-01 C- Type: 2 Theta - Start: $5.002^{\circ}$ - End: $67.859^{\circ}$ - Step: $0.010^{\circ}$ - Step time: $57 . \mathrm{s}$ - Temp.: $25^{\circ} \mathrm{C}$ (Room) - Time Started: 0 S - 2-Theta: 5.002 Lل101-072-1650 (C) - Calcite

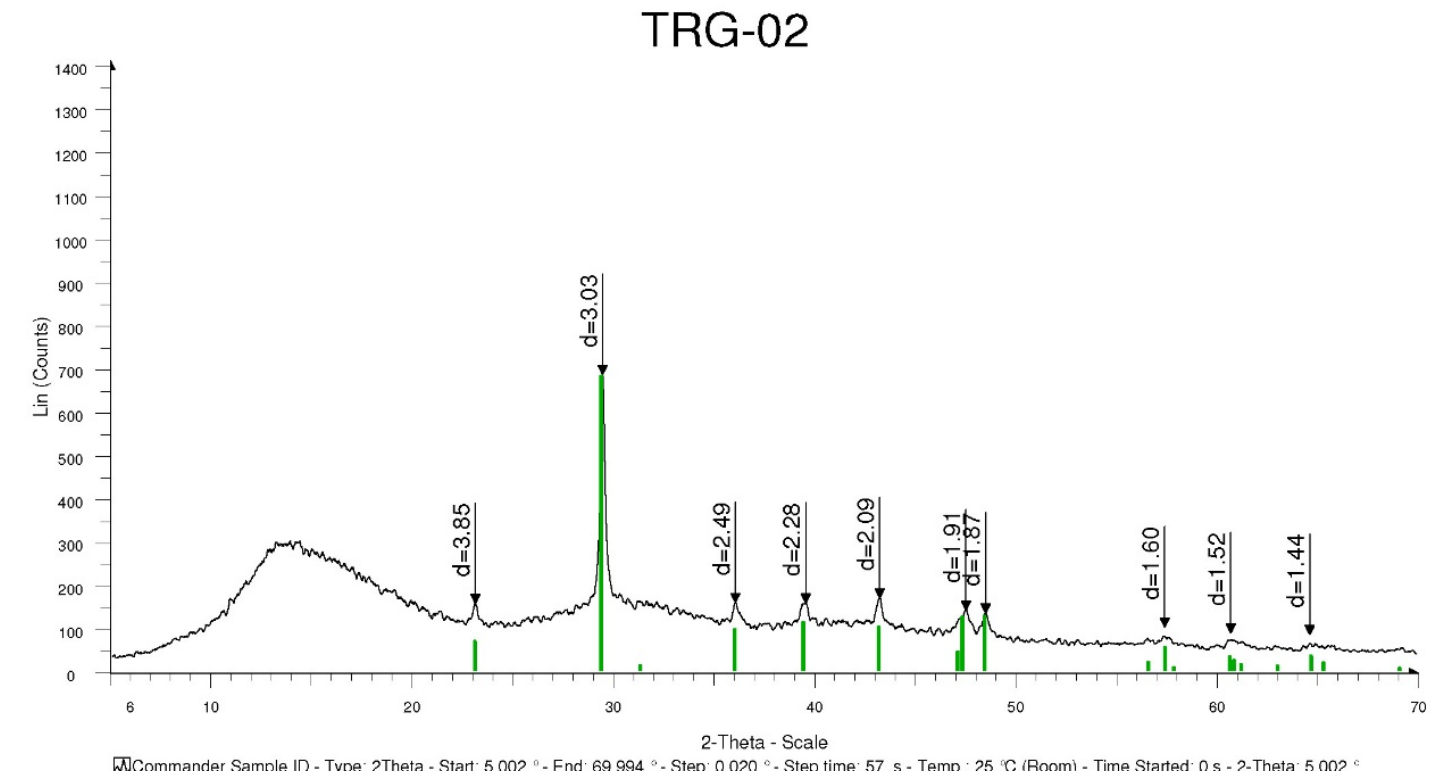

WhCommander Sample ID - Type: 2 Theta - Start: $5.002^{\circ}$ - End: $69.994^{\circ}$ - Step: $0.020^{\circ}$ - Step time: 57 . s - Temp.: $25^{\circ}$ C (Room) - Time Started: 0 s - 2-Theta: $5.002^{\circ}$ Uل101-086-2339 (C) - Calcite 
TRG-03 A

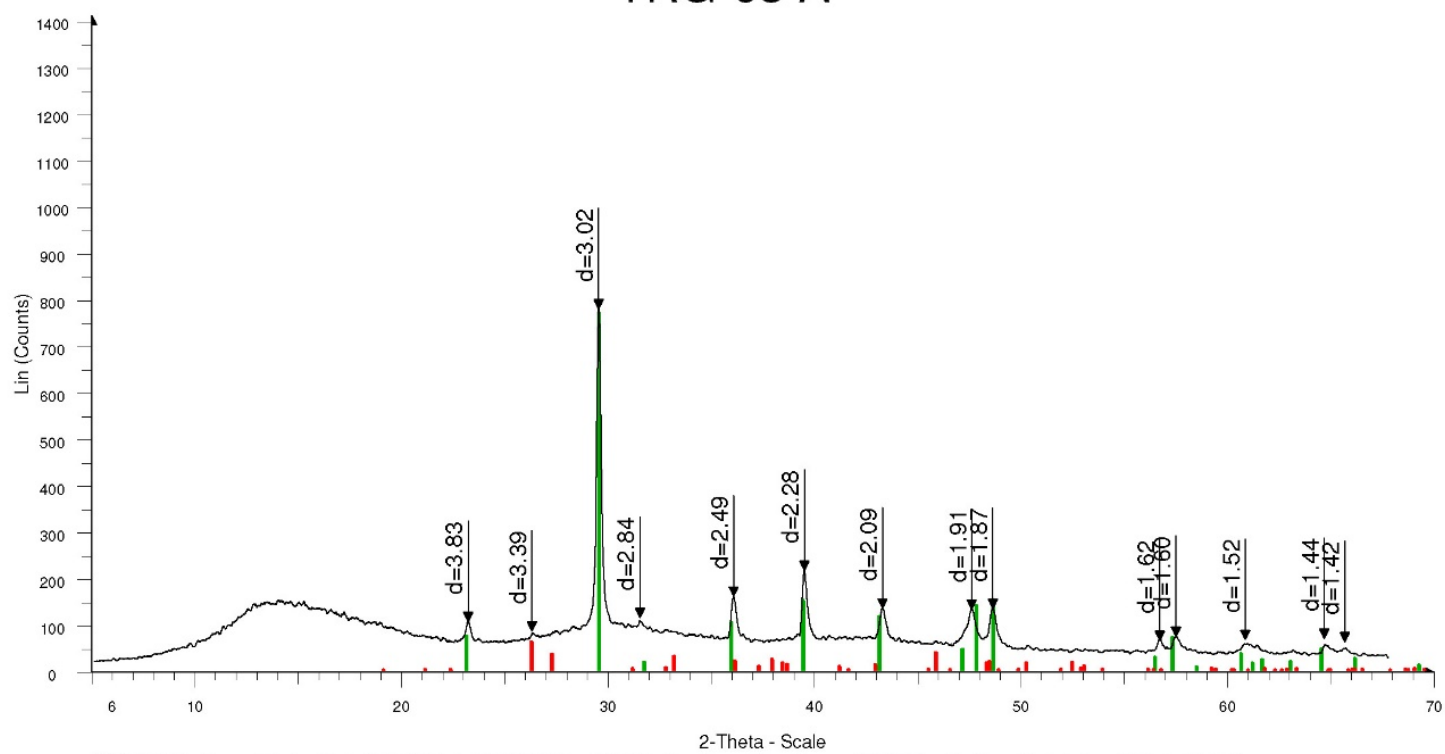

WTRG-03 A - Type: 2 Theta - Start: $5.002^{\circ}$ - End: $67.859^{\circ}$ - Step: $0.010^{\circ}$ - Step time: 57 . s - Temp.: $25^{\circ}$ C (Room) - Time Started: 0 s - 2-Theta: $5.002^{\circ}$ IIN $01-076-0606$ (C) - Aragonite
$\square 01-072-1650$ (C) - Calcite

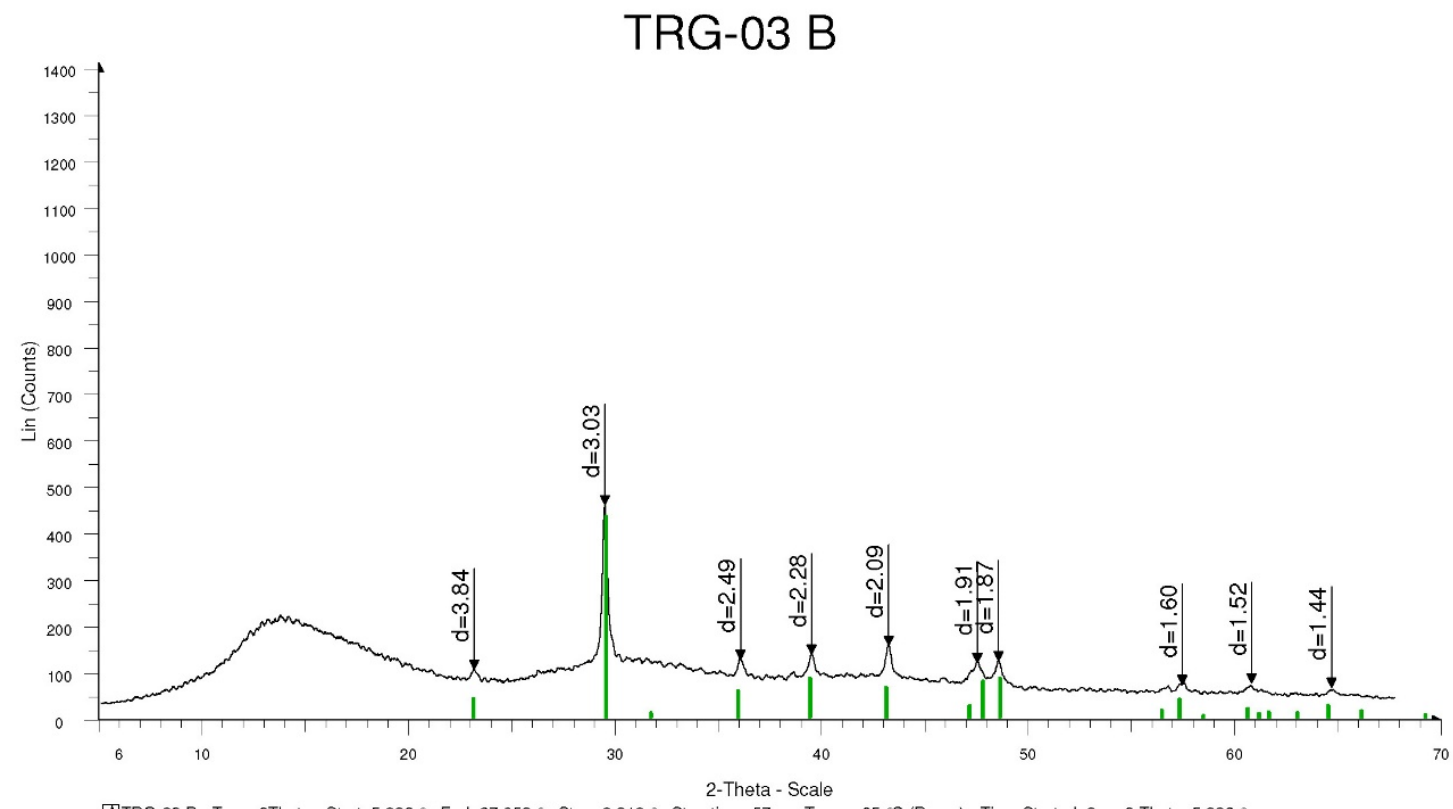

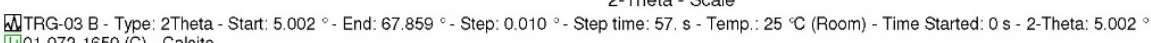
01-072-1650 (C) - Calcite 
TRG-03 C

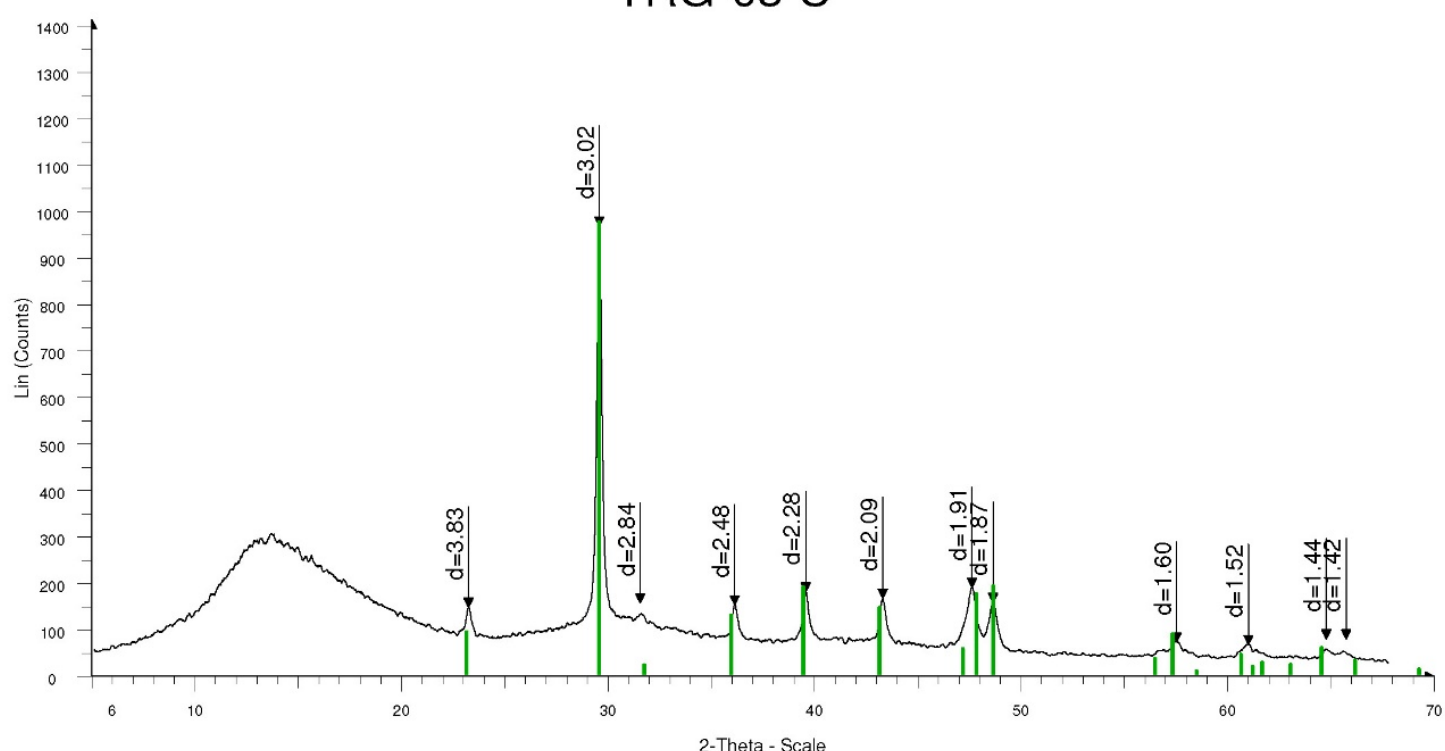

WTRG-03 C - Type: 2 Theta - Start: $5.002^{\circ}$ - End: $67.859^{\circ}$ - Step: $0.010^{\circ}$ - Step time: 57 . s - Temp.: $25^{\circ} \mathrm{C}$ (Room) - Time Started: 0 S - 2-Theta: 5.002 Lid $01-072-1650$ (C) - Calcite

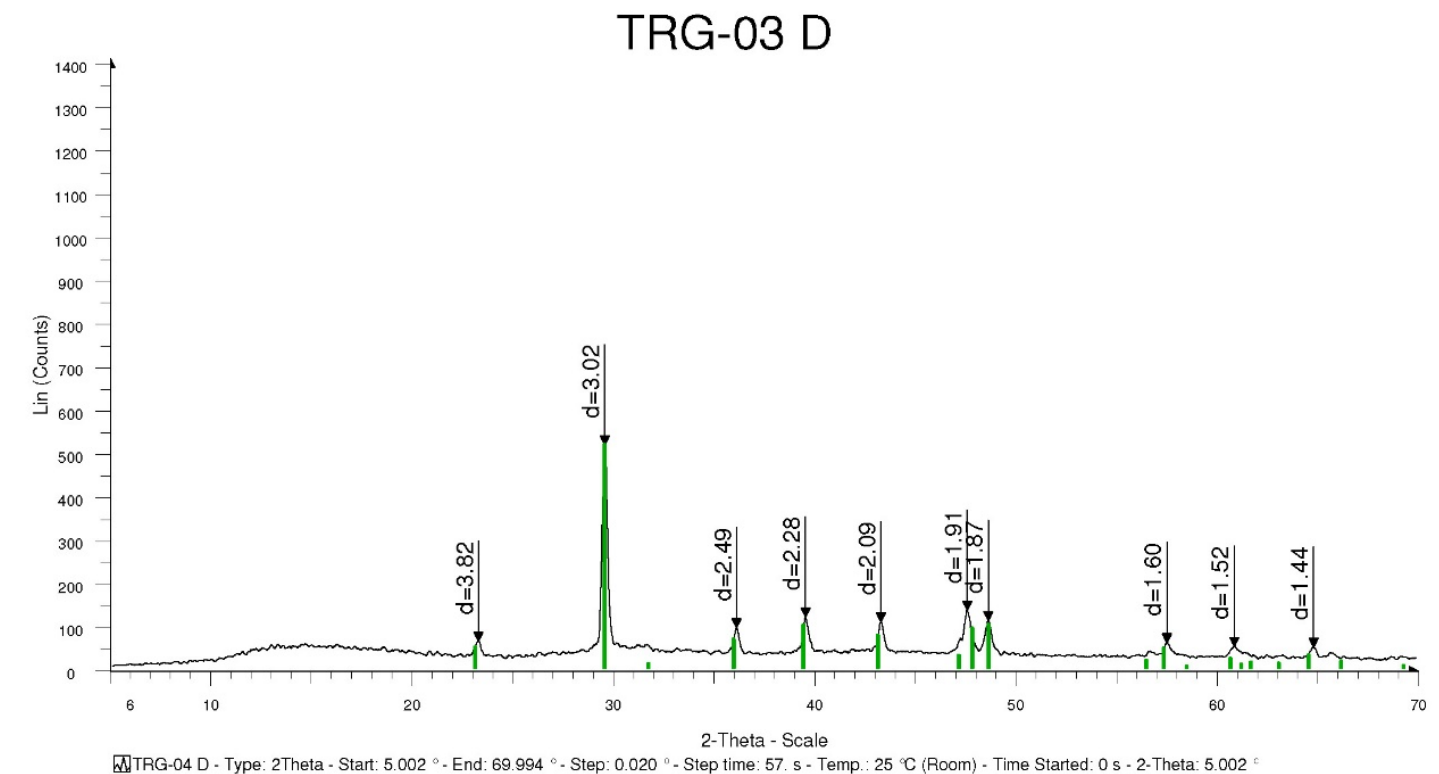

WTR-04 D - Type: 2 Theta - Start: $5.002^{\circ}$ - End: $69.994^{\circ}$ - Step: $0.020^{\circ}$ - Step time: 57 . s - Temp.: $25^{\circ} \mathrm{C}$ (Room) - Time Started: 0 s - 2-Theta: 5.002 
TRG-04 A

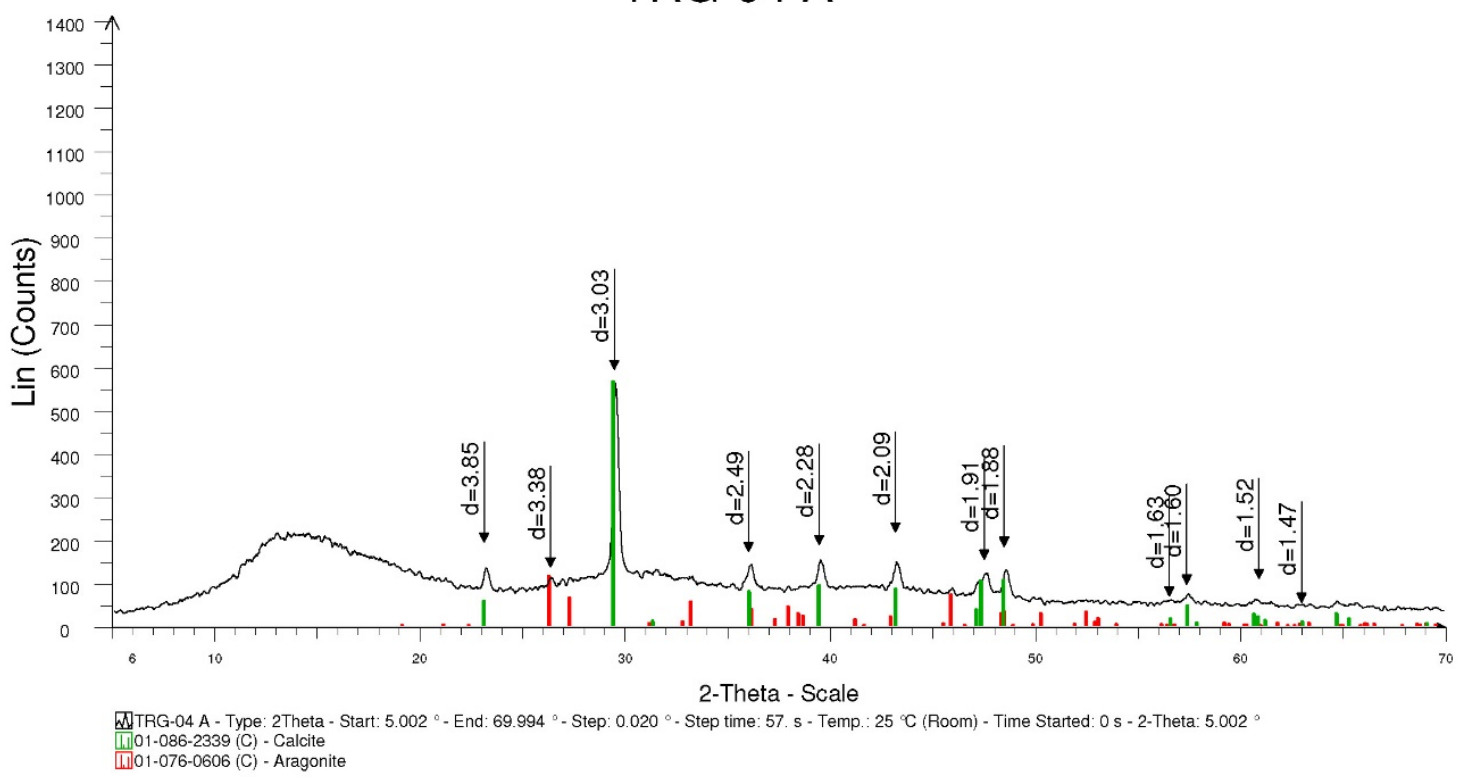

TRG-04 B

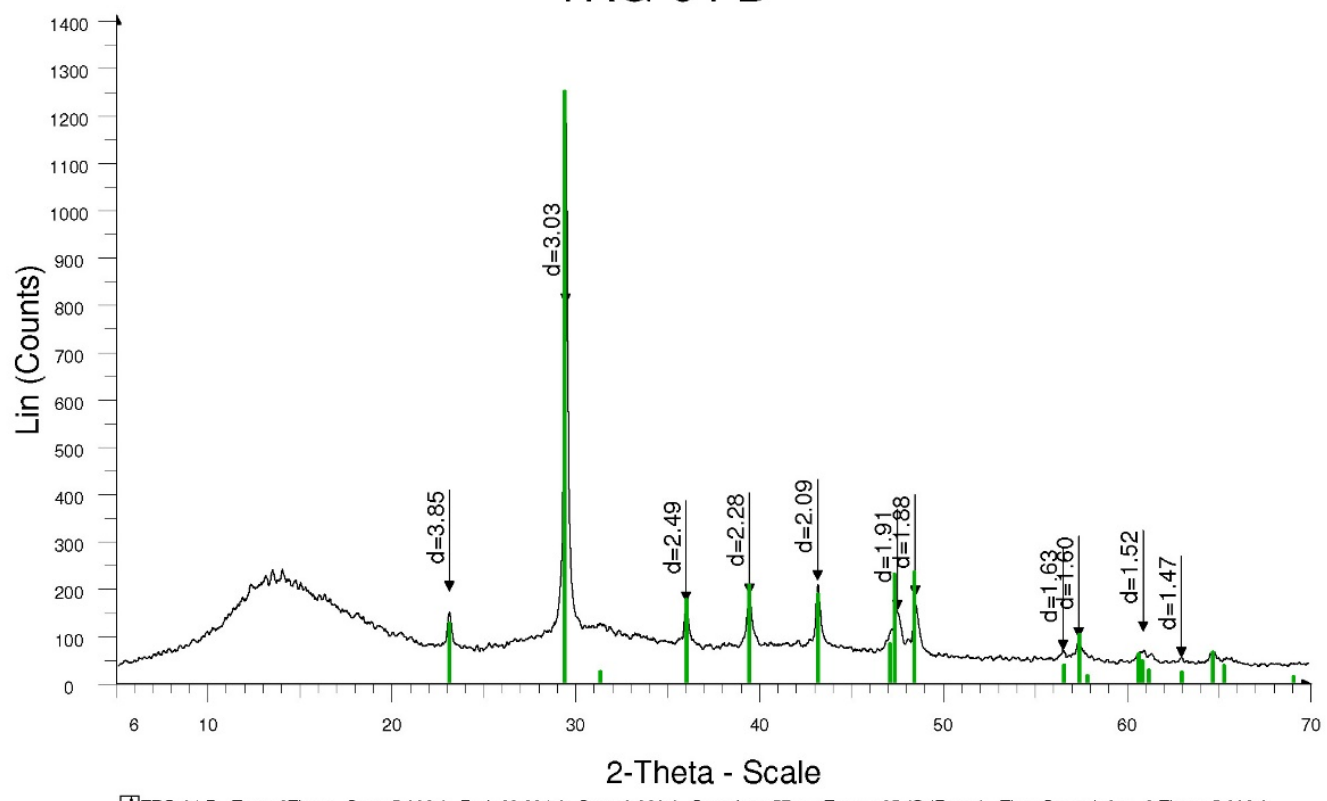

MTRG-04 B - Type: 2 Theta - Start: $5.002^{\circ}$ - End: $69.994^{\circ}$ - Step: $0.020^{\circ}$ - Step time: 57 . s - Temp.: $25{ }^{\circ}$ (Room) - Time Started: 0 s - 2-Theta: 5.002 Operations: Smooth 0.150 | Import W01-086-2339 (C) - Calcite 


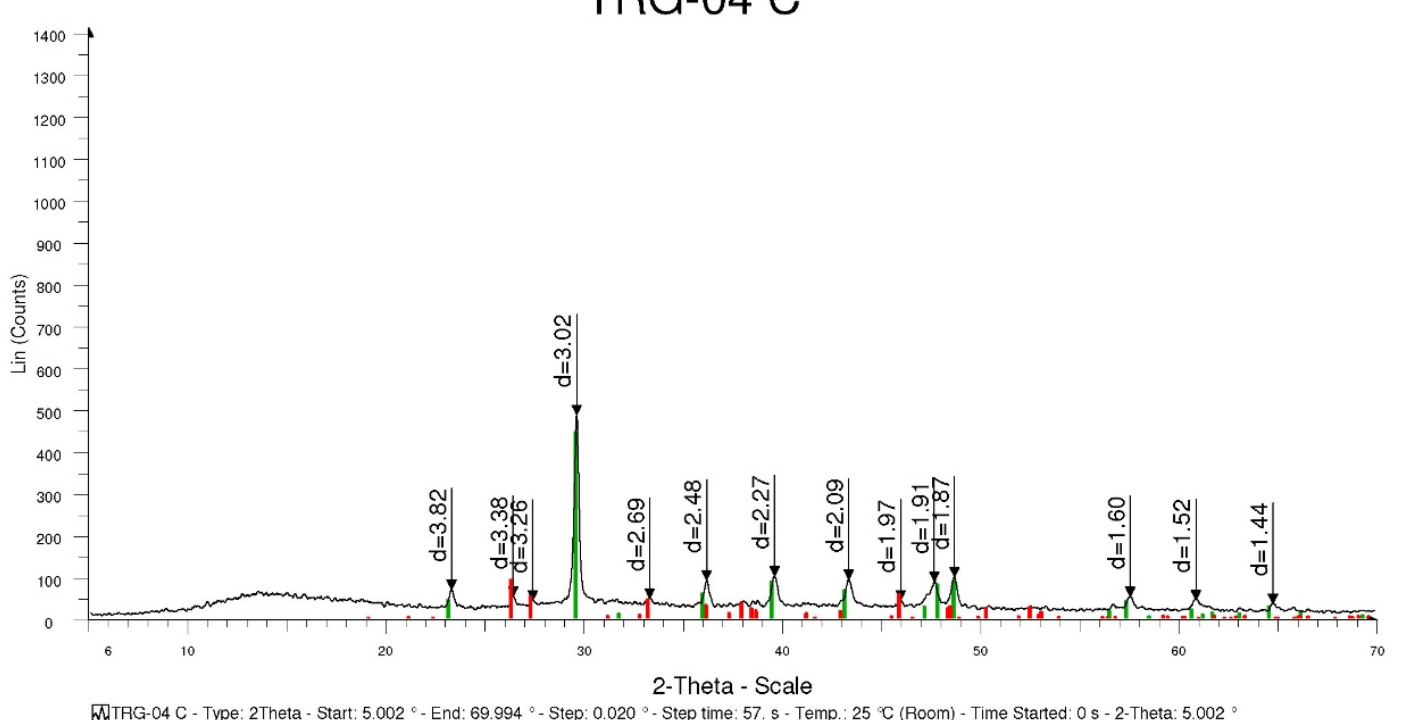

WTRG-04 C - Type: 2 Theta - Start: $5.002^{\circ}$ - End: $69.994^{\circ}$ - Step: $0.020^{\circ}$ - Step time: 57 . s - Temp.: $25^{\circ} \mathrm{C}$ (Room) - Time Started: 0 s - 2-Theta: $5.002^{\circ}$ I.] $01-072-1650$ (C) - Calcite

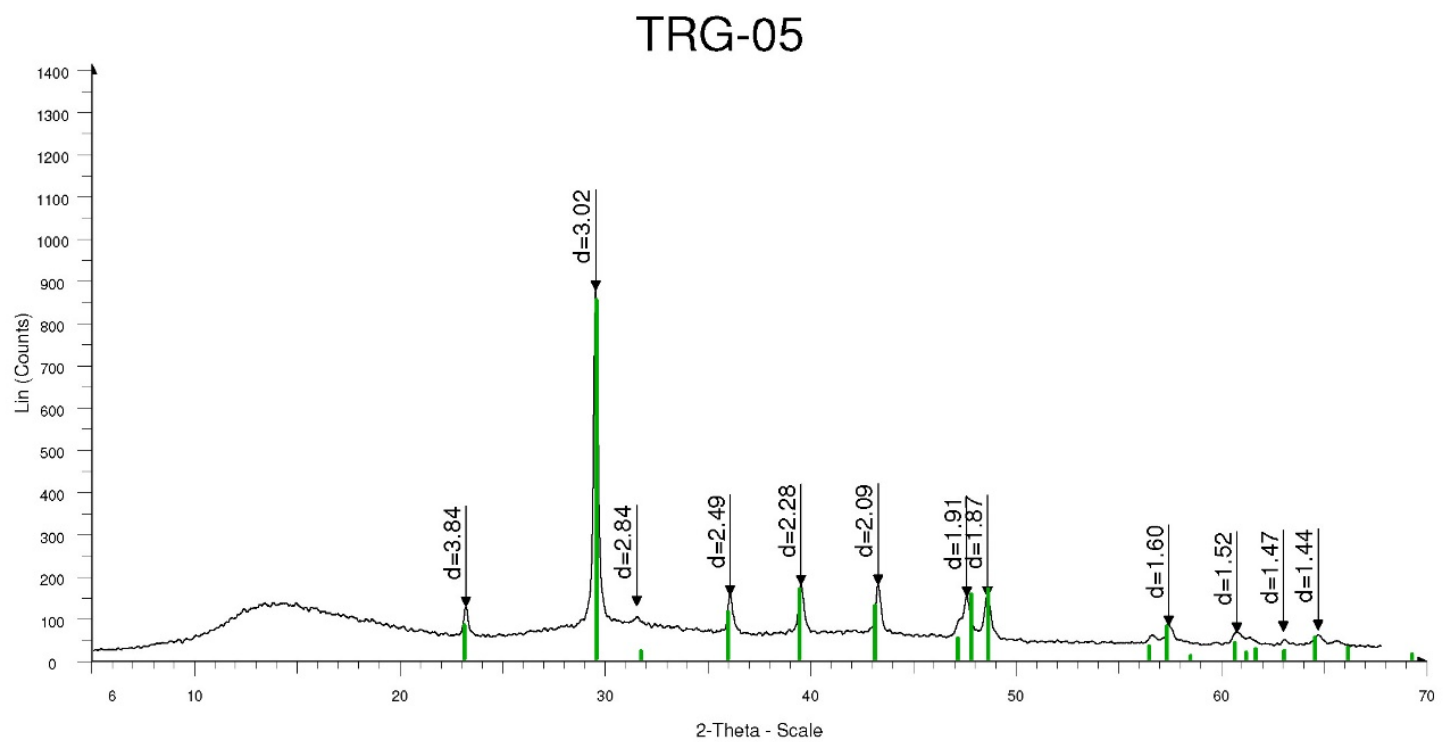

WTRG-05 - Type: 2 Theta - Start: $5.002^{\circ}$ - End: $67.859^{\circ}$ - Step: $0.010^{\circ}$ - Step time: 57 . s - Temp.: $25^{\circ} \mathrm{C}$ (Room) - Time Started: 0 s - 2-Theta: 5.002 1. 01-072-1650 (C) - Calcite 
Supplementary Figure S6: a) Short columnar calcite crystals alternating with brown micritic bands constitute the first calcite precipitates over the host rock. Plane polarised light (PPL); b) columnar calcite crystals predominantly oriented towards the right (downslope). Crossed polarised light (XPL); c) oriented columnar calcite crystals displaying signs of dissolution. Occasionally, both crystal layers are separated by a thin, wavy micritic layer possibly indicating dissolution processes (PPL); d) aragonitecalcite layered textures (right) and secondary calcite crystals with aragonite relicts, some of them arranged in fans aligned forming a band (PPL); e) secondary calcite showing abundant aragonite relicts and very anhedral textures (PPL); f) the same image as e, under crossed polarised light. Thin sections orientation is parallel to the former glacier sliding direction.
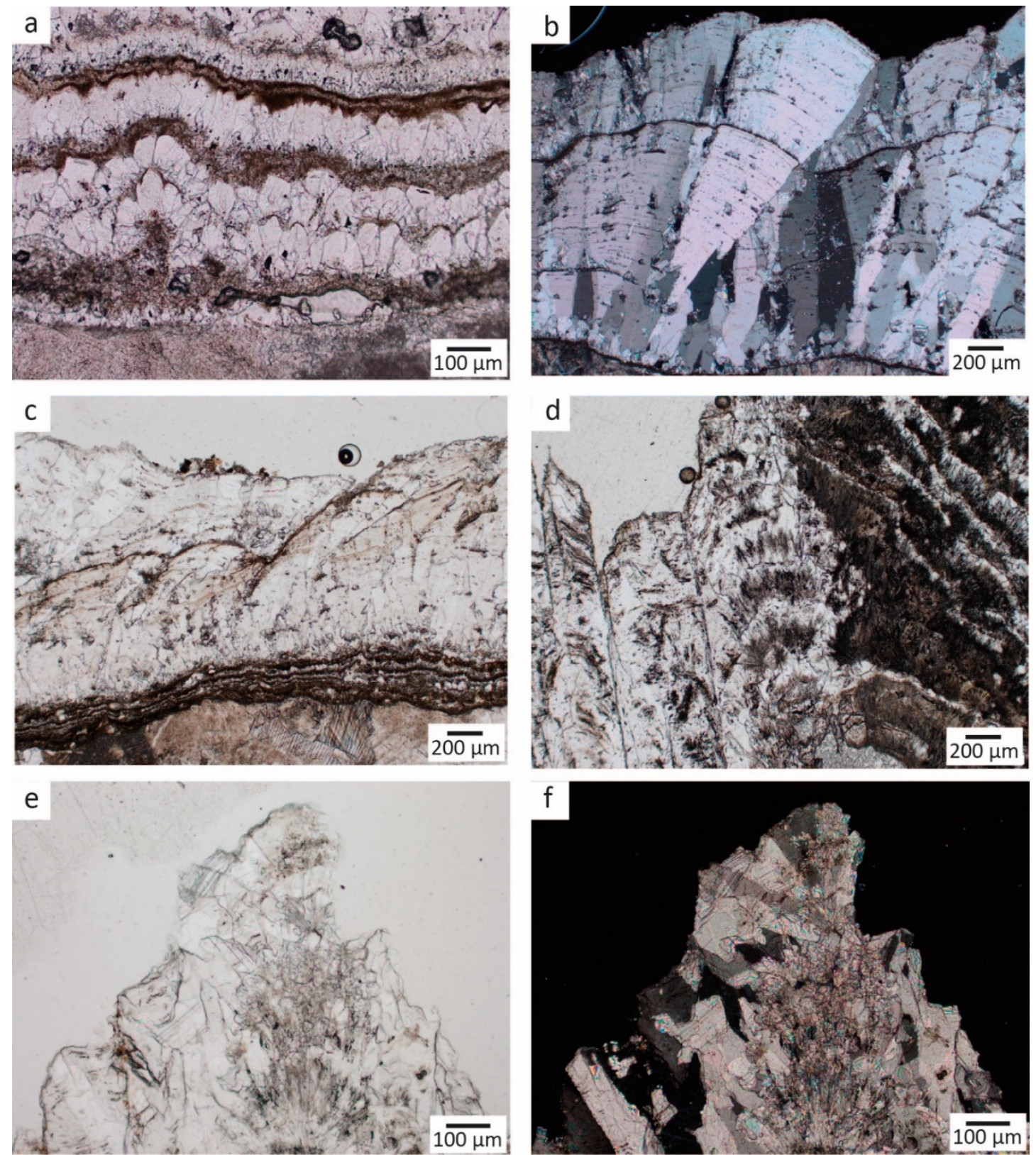
Supplementary Figure S7: The columnar and elongated columnar calcite crystals oriented downslope (plane polarised light - above, and crossed polarised light - below). Thin section orientation is parallel to the former glacier sliding direction.

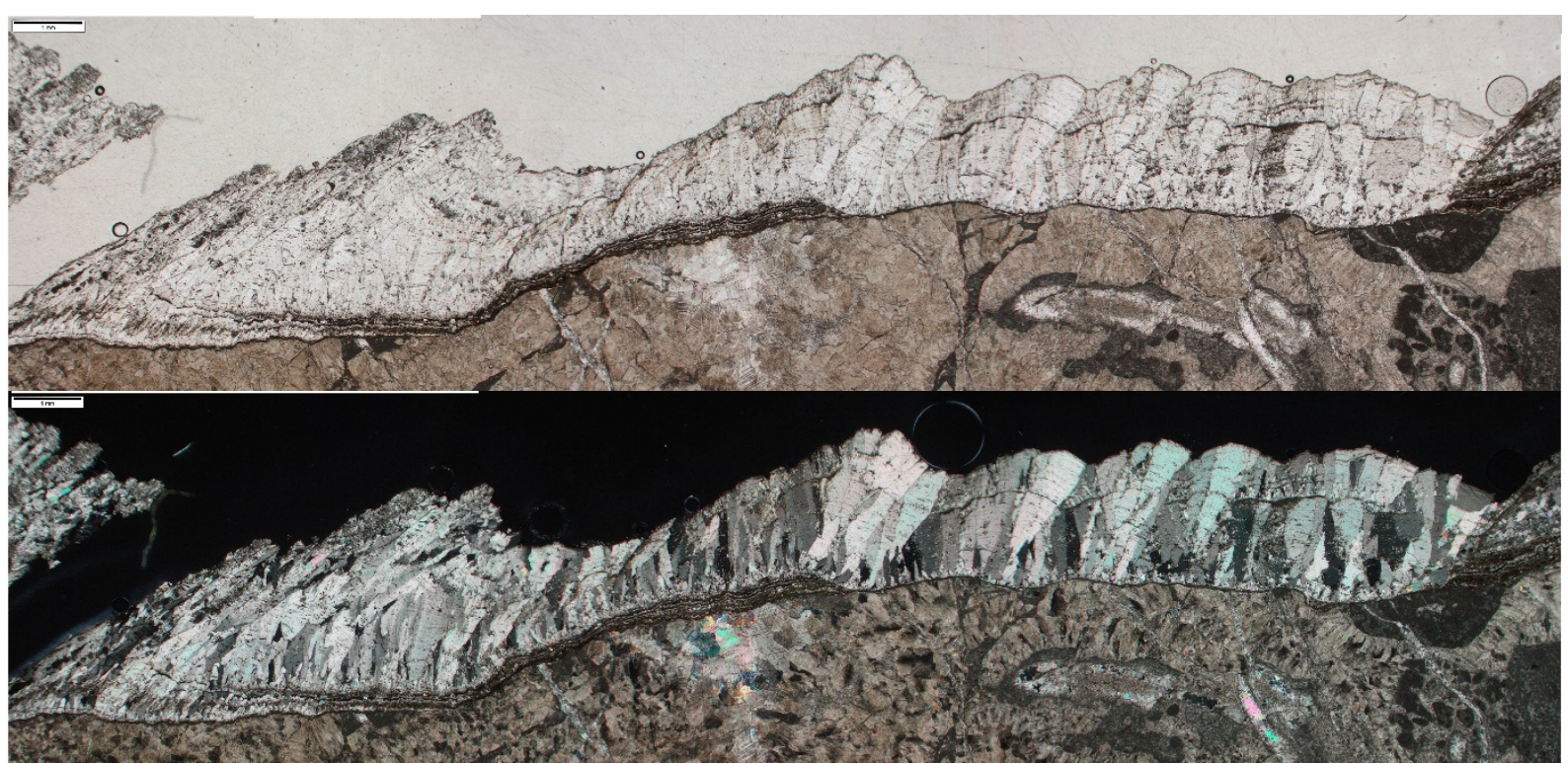


Supplementary Table S1: U-Th data for the subglacial calcite. Note: Ratios in parentheses are activity ratios calculated from the atomic ratios. Errors are at $2 \delta$ level. The ages are calculated using the Isoplot 3.75 Program of Ludwig (2012) with decay constants from Cheng et al. (2000). Corrected Ages were calculated assuming initial/detrital ${ }^{230} \mathrm{Th} /{ }^{232} \mathrm{Th}$ activity ratio equal $0.825 \pm 50 \%$ (the bulk-Earth value, which is the most commonly used for initial/detrital ${ }^{230} \mathrm{Th}$ corrections).

U-Th dating was carried out using a Nu Plasma multi-collector inductively-coupled plasma mass spectrometer (MC-ICP-MS) in the Radiogenic Isotope Facility (RIF) at the School of Earth and Environmental Sciences, The University of Queensland (UQ) following chemical treatment procedures and MC-ICP-MS analytical protocols described elsewhere (Zhao et al., 2009; Clark et al., 2012; Clark et al., 2014). Powdered or chipped sub-samples weighing 16-78 mg were spiked with a mixed ${ }^{229} \mathrm{Th}^{233} \mathrm{U}$ tracer and then completely dissolved in concentrated $\mathrm{HNO}_{3}$. After digestion, each sample was treated with $\mathrm{H}_{2} \mathrm{O}_{2}$ to decompose trace amounts of organic matters (if any) and to facilitate complete sample-tracer homogenisation. $U$ and Th were separated using conventional anion-exchange column chemistry using Bio-Rad AG 1-X8 resin. After stripping off the matrix from the column using double-distilled $7 \mathrm{~N} \mathrm{HNO}^{2}$ as eluent, $3 \mathrm{ml}$ of a $2 \% \mathrm{HNO}$ solution mixed with trace amount of HF was used to elute both U and Th into a 3.5-ml pre-cleaned test tube, ready for MC-ICP-MS analyses, without the need for further drying down and re-mixing. After column chemistry, the U-Th mixed solution was injected into the MC-ICP-MS through a DSN-100 desolvation nebuliser system with an uptake rate of around $0.07 \mathrm{ml}$ per minute. U-Th isotopic ratio measurement was performed on the MC-ICP-MS using a detector configuration to allow simultaneous measurements of both $U$ and Th isotopes (Zhou et al., 2011; Clark et al., 2014). The ${ }^{230} \mathrm{Th} /{ }^{238} \mathrm{U}$ and ${ }^{234} \mathrm{U} /{ }^{238} \mathrm{U}$ activity ratios of the samples were calculated using the decay constants given in (Cheng et al., 2000). The non-radiogenic ${ }^{230} \mathrm{Th}$ was corrected using an assumed bulk-Earth atomic ${ }^{230} \mathrm{Th} /{ }^{232} \mathrm{Th}$ ratio of $4.4 \pm 2.2 \times 10^{-6}$. U-Th ages were calculated using the Isoplot/Ex 3.75 Program (Ludwig, 2012).

T.01_a1

T.03_a1

T.03 a2

T.03_b1

T.05

\section{Sample}

wt.(g)

0,06022

0,07823

0,02380

0,01620

0,02151

$\begin{array}{rrr}\mathbf{U}(\mathbf{p p m}) & \pm 2 \mathbf{s} & \begin{array}{r}{ }^{232} \mathbf{T h} \\ \mathbf{( p p b )}\end{array} \\ 0,45584 & 0,00019 & 20,522 \\ 0,41066 & 0,00017 & 7,454 \\ 0,8933 & 0,0003 & 4,929 \\ 1,7737 & 0,0005 & 4,080 \\ 1,3305 & 0,0004 & 68,59\end{array}$

$\pm 2 \mathrm{~s}$

0,019

0,012

0,005

0,005

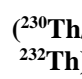 \\ $\left.{ }^{232} \mathrm{Th}\right)$}

10,945

19,219

19,99

24,49

12,20

$\pm 2 s$
0,047
0,103
0,23
0,23
0,05

${ }^{2}$

$\left({ }^{230} \mathbf{T h} /{ }^{238} \mathbf{U}\right)$
0,1624
0,1150
0,0363
0,0186
0,2072

$\begin{array}{rr} \pm 2 s & \left.{ }^{238} \mathbf{U}\right) \\ 0,0007 & 0,9787 \\ 0,0006 & 1,0053 \\ 0,0004 & 1,0062 \\ 0,0002 & 1,0079 \\ 0,0008 & 1,0060\end{array}$

$\pm 2 s$
0,0012
0,0005
0,0011
0,0008
0,0010

uncorr.
${ }^{230}$ Th Age

(ka)
Th Age$$
\text { (ka) }
$$$$
13,26
$$$$
13,26
$$$$
4,012
$$$$
2,027
$$$$
\text { 25,15 }
$$

$\pm 2 \mathrm{~s}$

0,10

0,07

0,047

0,019

corr. ${ }^{230} \mathrm{~T}$
Age $(\mathbf{k})$
18,4
12,7
3,84
1,959
23,62

corr.

${ }^{234} \mathrm{U} /$

$\left.{ }^{238} \mathrm{U}\right)$

$\pm 2$

$0,9773 \quad 0,0013$

$1,0055 \quad 0,0006$

$1,0063 \quad 0,0011$

$1,0079 \quad 0,0008$

$1,0065 \quad 0,0011$ 
References:

Cheng, H., Edwards, R. L., Hoff, J., Gallup, C. D., Richards, D. A., and Asmerom, Y.: The half-lives of uranium-234 and thorium-230, Chemical Geology, 169, 17-33, doi:10.1016/s0009-2541(99)00157-6, 2000.

Clark, T. R., Zhao, J.-X., Feng, Y.-x., Done, T. J., Jupiter, S., Lough, J., and Pandolfi, J. M.: Spatial variability of initial ${ }^{230} \mathrm{Th} /{ }^{232} \mathrm{Th}$ in modern Porites from the inshore region of the Great Barrier Reef, Geochimica et Cosmochimica Acta, 78, 99-118, doi:10.1016/j.gca.2011.11.032, 2012.

Clark, T. R., Zhao, J.-X., Roff, G., Feng, Y.-X., Done, T. J., Nothdurft, L. D., and Pandolfi, J. M.:

Discerning the timing and cause of historical mortality events in modern Porites from the Great Barrier Reef, Geochimica et Cosmochimica Acta, 138, 57-80, doi:10.1016/j.gca.2014.04.022, 2014. Gabrovec, M., Hrvatin, M., Komac, B., Ortar, J., Pavšek, M., Topole, M., Triglav Čekada, M., and Zorn, M.: Triglavski ledenik [Triglav Glacier], Založba ZRC, Ljubljana, 2014.

Ludwig, K. R.: User's manual for Isoplot version 3.75-4.15: a geochronological toolkit for Microsoft Excel, Berkeley Geochronological Center Special Publication, 5, 2012.

Zhao, J.-x., Yu, K.-f., and Feng, Y.-x.: High-precision ${ }^{238} \mathrm{U}-{ }^{234} \mathrm{U}-{ }^{230} \mathrm{Th}$ disequilibrium dating of the recent past: a review, Quaternary Geochronology, 4, 423-433, doi:10.1016/j.quageo.2009.01.012, 2009. Zhou, H., Zhao, J., Qing, W., Feng, Y., and Tang, J.: Speleothem-derived Asian summer monsoon variations in Central China, 54-46 ka, Journal of Quaternary Science, 26, 781-790, doi:10.1002/jqs.1506, 2011. 